\title{
Desenvolvimento vegetativo e produtivo da berinjela submetida a diferentes tensões de água no solo
}

\author{
Carolina Bilibio ${ }^{1}$, Jacinto A. Carvalho ${ }^{1}$, Minella Martins ${ }^{1}$, Fátima C. Rezende ${ }^{1}$, Elisangela A. Freitas ${ }^{1} \&$ Luis A. A. Gomes ${ }^{2}$
}

\section{RESUMO}

Os efeitos de diferentes tensões de água no solo aplicadas em dois estádios fenológicos da cultura da berinjela (Solanum melongena L.) foram avaliados por meio de dois experimentos, ambos conduzidos em um delineamento experimental inteiramente casualizado com 5 tratamentos e 6 repetições. 0 s tratamentos se constituíram de 5 diferentes tensões de água no solo: 15, 30, 45, 60 e $80 \mathrm{kPa}$. 0 s resultados permitiram concluir que efeitos significativos foram encontrados para todas as variáveis analisadas apenas quando os tratamentos foram aplicados na fase de formação de frutos/colheita, demonstrando que esta fase é mais sensível à escassez de água no solo, prejudicando o desenvolvimento da cultura; obtiveram-se maiores produções com irrigação realizada sob a tensão de $15 \mathrm{kPa}$.

Palavras-chave: manejo de irrigação, hortaliças, produtividade, Solanum melongena L.

\section{Vegetative growth and yield of eggplant under different soil water tensions}

\begin{abstract}
Effects of different water tensions in soil applied in two phenological stages in eggplant (Solanum melongena L.) crop were evaluated in two experiments, both carried out in a totally randomized experimental design with 5 treatments and 6 repetitions. The treatments consisted of 5 different soil water tensions: 15, 30, 45, 60 and $80 \mathrm{kPa}$. The results showed significant efects on all the analysed variables only when treatments were applied in the fruit formation/harvest phase, showing that this phase is more sensitive to soil water tensions and which damages crop development. The best yields were obtained with irrigation carried out under $15 \mathrm{kPa}$ tension.
\end{abstract}

Key words: irrigation management, phenological stages, yield, Solanum melongena L.

\footnotetext{
1 Departamento de Engenharia/UFLA, CP 3037, CEP 37200-000, Lavras, MG. Fone (35) 3829-1481. E-mail: carolina.bilibio@yahoo.com.br; jacintoc@deg.ufla.br; minella.martins@hotmail.com; frezende@deg.ufla.br; elisa_alves2005@hotmail.com

2 Departamento de Agricultura/UFLA E-mail: laagomes@dag.ufla.br
} 


\section{INTRODUÇÃO}

O agronegócio é o setor responsável por pelo menos $35 \%$ do PIB brasileiro, tal como o setor das frutas e hortaliças por 3,5\% do PIB agrícola (Vilela \& Henz, 2000). A produção brasileira anual de hortaliças atinge cerca de 12,5 milhões de toneladas (Grangeiro \& Cecílio Filho, 2004), com projeções de crescimento (Vilela \& Henz, 2000) principalmente daquelas com propriedades fitoterápicas (Cardoso et al., 2008).

Neste contexto se destaca a berinjela (Solanum melongena L.) que, de acordo com Ribeiro (2007) apresentou, em 1996, uma produção de 30,7 mil toneladas, das quais a região Sudeste participou com $88,79 \%$ da produção destacando-se, sobremaneira, São Paulo (60,74\%), Rio de Janeiro $(12,43 \%)$ e Minas Gerais $(14,32 \%)$. Atualmente, é cultivada em aproximadamente 1.500 ha no Brasil e com demanda crescente devido às propriedades medicinais dos frutos, como redução do nível de colesterol (Antonini et al., 2002), e por representarem boa fonte de sais minerais e vitaminas (Gonçalves et al., 2006).

O clima favorável ao desenvolvimento da berinjela é tipicamente tropical, favorecido pelo calor (Filgueira, 2000). A colheita se inicia aos 100 dias da semeadura, podendo prolongar-se por mais 100 dias. Os frutos são colhidos antes do crescimento total, com 20-22 cm de comprimento. A cultura exige boa luminosidade e solos excessivamente úmidos prejudicam o desenvolvimento, em virtude de deficiência de oxigênio para as raízes. A maior limitação para o cultivo é a umidade no solo inadequada durante seu ciclo, como ocorre na maioria das hortaliças (Marouelli et al., 1996).

Desta forma, a irrigação, entendida como a aplicação de água ao solo no qual se desenvolve a agricultura, é uma técnica disponível que tem o objetivo de suplementar a chuva para manter os teores de água no solo ideais ao desenvolvimento das culturas aumentando, assim, o crescimento das plantas, a qualidade do produto e a produtividade do cultivo. O manejo adequado da irrigação, que envolve a decisão de quando e quanto irrigar, visa maximizar a eficiência do uso da água, minimizar o consumo de energia e manter favoráveis as condições de umidade do solo e de fitossanidade das plantas (Marouelli et al., 1996).

Sá et al. (2005) obtiveram maiores produtividades comercial e total e menor incidência de frutos com podridão apical em tomate, cultivado em ambiente protegido e irrigado por gotejamento, com irrigações realizadas quando a tensão de água no solo, a $0,10 \mathrm{~m}$ de profundidade, era de $80 \mathrm{kPa}$.

Marques (2003) estudou o efeito da salinização nos componentes de rendimento da berinjela no município de Lavras e verificou que a salinidade na água de irrigação reduz a produção total da cultura e a produção comercial. Carvalho et al. (2004), avaliaram os efeitos de diferentes níveis de déficit hídrico aplicados em dois estádios fenológicos da cultura da berinjela e constataram que a produção e o número de frutos foram mais afetados pelo déficit hídrico quando este ocorreu durante a fase de formação dos frutos.

Moura et al. (2004) notaram, em estudo com a irrigação com água salina na cultura da berinjela, que a evapotranspiração da cultura diminuiu linearmente com o aumento da concentração de sais na água de irrigação e, ainda, que a produção da cultura foi afetada pelo déficit hídrico.

Particular atenção deve ser dada ao déficit hídrico uma vez que o mesmo afeta significativamente a produção da cultura, sobretudo quando ocorre na fase de florescimento e no aspecto qualitativo, quando ocorre durante o período reprodutivo (Fabeiro et al., 2002; Lovelli et al., 2007; Aujla et al., 2007; Posse et al., 2009)

Critérios para estabelecer o momento de quando irrigar podem ser baseados em função do potencial matricial crítico da água no solo sendo as culturas, em geral, mais sensíveis a potenciais baixos (mais negativos) em determinados estádios de crescimento que outras, porém poucos estudos têm sido feitos para avaliar o momento ideal de se efetuar a irrigação na cultura da berinjela, razão pela qual se objetivou, nesta pesquisa, avaliar o efeito de diferentes tensões da água no solo aplicadas em dois estádios fenológicos, sobre as características produtivas e vegetativas da berinjela, cultivar Nápoli, cultivada em ambiente protegido, na Região Sul de Minas Gerais.

\section{MATERIAL E MÉTODOS}

Dois experimentos foram conduzidos em casa de vegetação no Departamento de Engenharia, da Universidade Federal de Lavras, município de Lavras, MG, no período de abril a outubro de 2008. O município está localizado na Região Sul do Estado de Minas Gerais, a $918 \mathrm{~m}$ de altitude, $21^{\circ} 14^{\prime}$ de Latitude Sul e $45^{\circ} 00^{\prime}$ de Longitude Oeste. Segundo a classificação de Köppen a região apresenta um clima $\mathrm{Cwa}$, ou seja, clima temperado suave, chuvoso, com inverno seco, temperatura média do mês mais frio inferior a $18{ }^{\circ} \mathrm{C}$ e superior a $3{ }^{\circ} \mathrm{C}$, o verão apresenta temperatura média do mês mais quente, superior a $22{ }^{\circ} \mathrm{C}$ (Dantas et al., 2007).

As condições ambientais foram monitoradas diariamente através da leitura da temperatura e umidade relativa do ar, com o auxílio de um termohigrômetro digital, cujas leituras eram realizadas diariamente, às $17 \mathrm{~h}$.

Utilizou-se, para ambos os experimentos, o delineamento inteiramente casualizado com 6 repetições. Os tratamentos compreendiam 5 níveis de tensão de água no solo $(15,30$, 45, 60 e $80 \mathrm{kPa}$ ). No primeiro experimento (experimento 1) se avaliou o efeito dos tratamentos na fase de pós transplante/abertura da gema floral e, no segundo experimento (experimento 2) o efeito dos tratamentos na fase de formação de frutos/colheita. As análises estatísticas foram realizadas com o software R (R Development Core Team, 2008).

Mudas de berinjela, híbrido Nápoli, foram transplantadas para vasos de polietileno com capacidade de $21 \mathrm{dm}^{3}$. O solo utilizado no preenchimento dos vasos, classificado como Latossolo Vermelho distrófico Típico (EMBRAPA, 1999), foi retirado de uma camada subsuperficial, secado ao ar, destorroado e passado em peneira com malha de $4 \mathrm{~mm}$. Realizaramse análises físicas e químicas do solo no Departamento de Ciência do Solo da Universidade Federal de Lavras, em que o solo foi classificado como muito argiloso, enquanto a condutividade elétrica do estrato saturado foi de $0,25 \mathrm{mS} \mathrm{cm}^{-1}$. 
Obtiveram-se os parâmetros da equação de ajuste da curva característica de retenção de água no solo com o auxílio do software SWRC (Soil Water Retention Curve, Dourado Neto et al., 2000), e se encontram na Eq. 1.

$$
\theta=0,230+\left(\frac{0,4760-0,230}{\left[1+(\psi \cdot 2382)^{1,8189}\right]^{0,4502}}\right)
$$

A adubação foi realizada com base nos resultados da análise de fertilidade do solo e de acordo com as recomendações da $5^{\text {a }}$ Aproximação da Comissão de Fertilidade do Solo do Estado de Minas Gerais (CFSEMIG, 1999). A adubação de cobertura foi realizada quinzenalmente, com Nitrato de Cálcio ( $17 \%$ de $\mathrm{N}$ e $18 \% \mathrm{Ca})$.

Os tratos culturais consistiram na retirada dos brotos que surgiram antes da inserção da primeira flor, tutoramento com estacas de bambu para promover a condução das plantas e aplicações preventivas quinzenais com fungicida.

Irrigaram-se as plantas utilizando-se o sistema de gotejamento por gravidade, com emissores inseridos sobre a linha. Realizou-se o manejo da irrigação a partir da leitura da tensão nos tensiômetros instalados a $12,5 \mathrm{~cm}$ de profundidade nas unidades experimentais de 15, 30 e $45 \mathrm{kPa}$; nas tensões de 60 e $80 \mathrm{kPa}$ foi utilizado o Watermark ${ }^{\circledR}$.

Observadas as tensões, calcularam-se as umidades correspondentes, a partir da curva característica de retenção de água no solo. De posse dessas umidades e daquela correspondente à capacidade de campo e, ainda, considerando-se o volume de solo presente no vaso, calculou-se o volume de reposição.

Até 10 dias após o transplante das mudas todos os tratamentos foram irrigados igualmente, de forma a garantir o pegamento das mudas; após este período se iniciou a aplicação dos tratamentos no experimento 1 , referente à primeira fase fenológica (pós-transplante/abertura da gema floral) até a época em que $50 \%$ das flores das plantas se encontravam abertas; a partir deste momento foram suspensos os tratamentos e todas as unidades experimentais deste experimento passaram a ser irrigadas quando a tensão atingia $15 \mathrm{kPa}$; na mesma época as unidades experimentais a serem avaliadas na fase produtiva foram então submetidas a diferentes condições de tensão de água no solo, até o final do ciclo.

A produtividade por planta $(\mathrm{kg})$ foi avaliada além da altura, com uma trena de metal e diâmetro do caule, com o auxílio de um paquímetro. Os dados foram submetidos a análise de variância, cujo efeito dos tratamentos foi estudado por meio de análise de regressão.

A quantificação do efeito do déficit hídrico sobre a produtividade foi feita mediante a relação entre a queda de rendimento relativo e o déficit de evapotranspiração relativa, dada pelo coeficiente de resposta Ky (Doorenbos \& Kassan, 1994), sendo:

$$
\left(1-\frac{\mathrm{Yr}}{\mathrm{Ym}}\right)=\mathrm{Ky} \cdot\left(1-\frac{\mathrm{ETr}}{\mathrm{ETm}}\right)
$$

em que:

Yr - rendimento real obtido

$\mathrm{Ym}$ - rendimento potencial obtido
Ky - coeficiente de resposta da cultura

$\mathrm{ETr}$ - evapotranspiração real

ETm - evapotranspiração potencial.

Obtiveram-se o rendimento potencial (Ym) e a evapotranspiração potencial (ETm) dos tratamentos correspondentes à tensão de $15 \mathrm{kPa}$, enquanto o rendimento real (Yr) e a evapotranspiraão real (ETr) foram obtidos dos diferentes tratamentos.

\section{RESULTADOS E DISCUSSÃO}

Durante o período de condução do experimento a temperatura máxima média e mínima média observada foi de 29,09 e $12,71{ }^{\circ} \mathrm{C}$, respectivamente (Figura $1 \mathrm{~A}$ ). A umidade relativa do ar máxima média e mínima média foi de 82 e $34 \%$, respectivamente (Figura 1B).

Esses valores são inferiores àqueles relatados por Ribeiro (2007) em que, sendo originária de clima tropical e subtropical, a berinjela se desenvolve bem em regiões de clima quente (a temperatura média durante o dia varia de 25 a $35^{\circ} \mathrm{C}$, a temperatura noturna varia de 20 a $27^{\circ} \mathrm{C}$ ) e a umidade relativa do ar seria de $80 \%$. O autor destaca, ainda, que temperatura média abaixo de $14{ }^{\circ} \mathrm{C}$ inibe o crescimento, floração e frutificação. Temperaturas acima de $32{ }^{\circ} \mathrm{C}$ aceleram a maturação dos frutos e temperaturas acima de $35^{\circ} \mathrm{C}$ por longos períodos de tempo inviabilizam o pólen e impedem a plena fertilização, resultando em frutos defeituosos (Marques, 2003).

$\mathrm{Na}$ Tabela 1 se apresentam as épocas de início e final de cada estádio fenológico (em dias após transplante das mudas), e sua duração. Como se observa no experimento 2, as plantas foram submetidas aos tratamentos por um período de tempo maior que no experimento 1 .

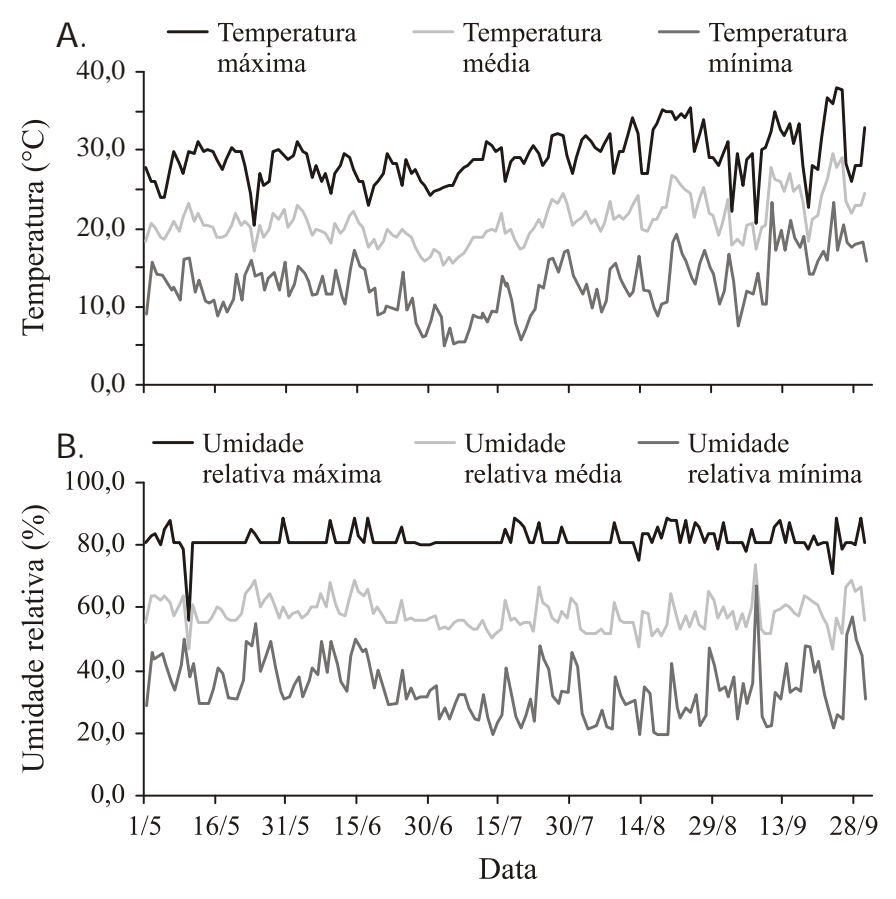

Figura 1. Temperatura máxima, mínima e média (A) e umidade relativa máxima, mínima e média (B) observada durante a condução do experimento 
Tabela 1. Início, final e duração dos estádios fenológicos da

\begin{tabular}{lccc}
\hline Fases Fenológicas & $\begin{array}{c}\text { Inicio } \\
\text { (DAT*) }\end{array}$ & $\begin{array}{c}\text { Final } \\
\text { (DAT) }\end{array}$ & $\begin{array}{c}\text { Duração } \\
\text { (Dias) }\end{array}$ \\
Experimento $1^{* *}$ & 10 & 34 & 24 \\
Experimento 2*** & 35 & 167 & 137 \\
\hline *DAT - dias após transplante das & mudas; **Pós- transplantante/ Abertura da Gema; \\
***Formação dos Frutos/Colheita & & &
\end{tabular}

Tem-se, na Tabela 2, o resumo dos resultados da análise de variância para o experimento 1, fase de pós-transplante/ abertura da gema floral.

Tabela 2. Análise de variância de diâmetro do caule $(\mathrm{mm})$, altura de planta $(\mathrm{cm})$ e produtividade ( $\mathrm{kg} \mathrm{planta}^{-1}$ ) em função de diferentes tensões de água no solo durante a fase de pós-

\begin{tabular}{ccccc}
\hline \multirow{2}{*}{ FV } & GL & \multicolumn{3}{c}{ QM } \\
\cline { 3 - 5 } & & Diâmetro caule & Altura planta & Produtividade \\
Tratamentos & 4 & $4,20^{\text {ns }}$ & $34,28^{\text {ns }}$ & $0,16^{\text {ns }}$ \\
Erro & 25 & 2,09 & 30,95 & 0,10 \\
CV (\%) & & 8,68 & 5,58 & 23,86 \\
Média & & 16,63 & 99,63 & 1,34 \\
\hline
\end{tabular}

ns - não significativo pelo teste $\mathrm{F}$ a $5 \%$ de probabilidade

Os tratamentos aplicados na fase de pós-transplante/abertura da gema floral não apresentaram diferença significativa, o que pode ser atribuído ao curto período em que as plantas ficaram submetidas aos tratamentos, ou seja, 24 dias; após este período as plantas deste experimento receberam reposição integral do volume recomendado, sendo a irrigação realizada quando a tensão da água no solo atingia $15 \mathrm{kPa}$.

A Tabela 3 apresenta o resumo da análise de variância para o experimento 2; verificou-se que, quando os tratamentos foram aplicados na fase de desenvolvimento dos frutos/ colheita, a altura das plantas, o diâmetro do caule e a produtividade foram afetados pelas diferentes tensões de água no solo.

O diâmetro do caule apresentou resposta linear em relação às tensões de água no solo (Figura 2A), indicando que, para cada variação unitária crescente da tensão de água no solo, ocorreu uma diminuição de $0,0702 \mathrm{~mm}$ no diâmetro do caule das plantas. Carvalho et al. (2004) verificaram que deficiências hídricas no período de formação dos frutos/colheita provocaram redução entre 10,92 a $24,22 \%$ nos valores do diâmetro do caule na cultura da berinjela.

A altura das plantas apresentou resposta linear em relação às tensões de água no solo (Figura 2B), indicando que,

Tabela 3. Análise de variância de diâmetro do caule $(\mathrm{mm})$, altura de planta $(\mathrm{cm})$ e produtividade ( $\left.\mathrm{kg} \mathrm{planta}^{-1}\right)$ em função de diferentes tensões de água no solo durante a fase de

\begin{tabular}{crccc}
\hline \multirow{2}{*}{ FV } & GL & \multicolumn{3}{c}{ QM } \\
\cline { 3 - 5 } & & Diâmetro caule & Altura planta & Produtividade \\
Tratamentos & 4 & $20,85^{*}$ & $799,42^{*}$ & $2,76^{*}$ \\
Erro & 25 & 2,20 & 31,48 & 0,02 \\
CV (\%) & & 10,12 & 6,28 & 21,32 \\
Média & & 14,65 & 89,33 & 0,72 \\
\hline
\end{tabular}

* - significativos a $5 \%$ de probabilidade pelo teste $\mathrm{F}$
A.

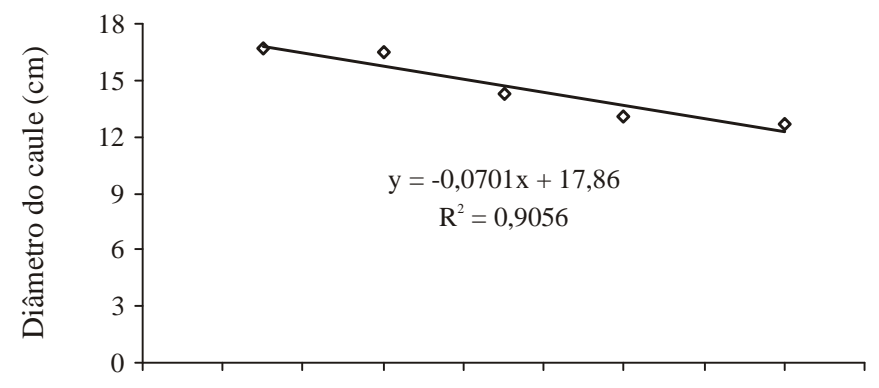

B.

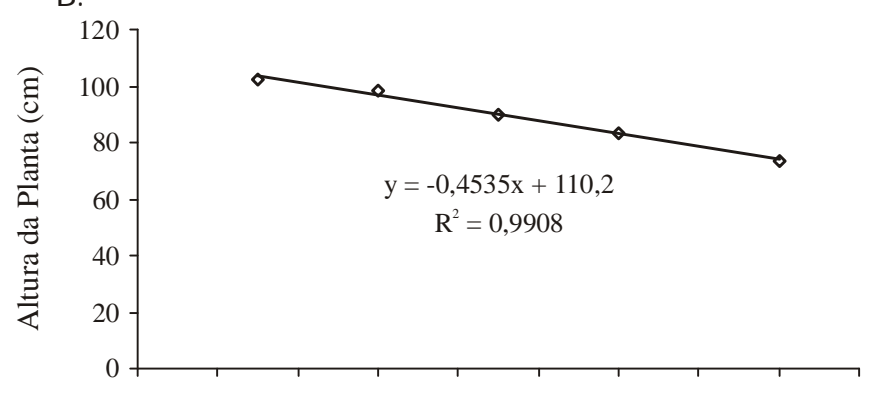

C.

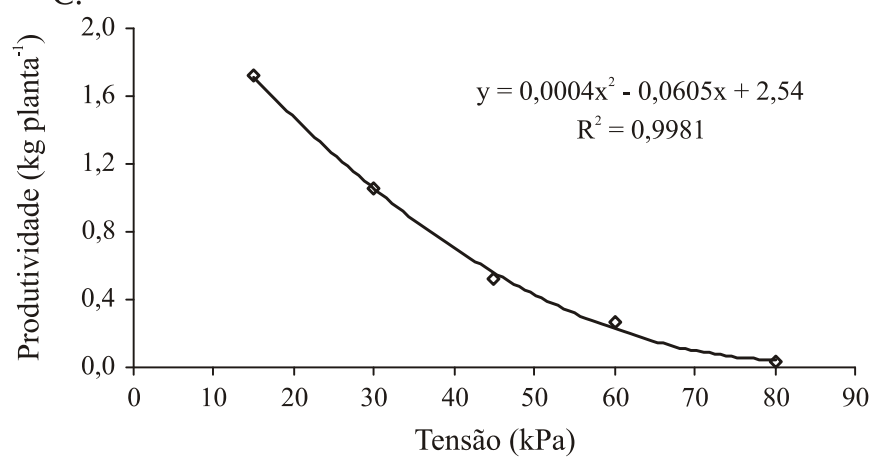

Figura 2. Efeito de diferentes tensões de água no solo no diâmetro do caule (A), na altura da planta (B) e na produtividade (C) na fase de formação dos frutos/ colheita

para cada variação unitária crescente da tensão de água no solo, deu-se uma redução de $0,4533 \mathrm{~cm}$ na altura das plantas. Carvalho et al. (2004) verificaram que deficiências hídricas no período de formação dos frutos/colheita provocaram redução média de $15 \%$ nos valores da altura das plantas da berinjela, aos 80 e 100 dias após o transplantio.

A produtividade total $\left(\mathrm{kg}_{\mathrm{g} \text { planta }}{ }^{-1}\right)$ pode ser explicada por um modelo quadrático, indicando que houve um decréscimo na produtividade total, à medida em que se aumentava a tensão de água no solo (Figura 2C). O ponto de maior produtividade foi obtido com a tensão de $15 \mathrm{kPa}$, equivalente a uma produtividade média observada de $1,72 \mathrm{~kg}$ planta $^{-1}$. Marouelli et al. (2002) verificaram maior desenvolvimento vegetativo, produtividade total e massa média de bulbos de uma cultivar de alho com tensões de 15 a $19 \mathrm{kPa}$ e recomendam realizar a irrigação em regime de alta frequência. Marouelli \& Silva (2006) concluíram que a tensão matricial crítica que maximizou a produtividade do tomateiro para processamento, durante o estádio de frutificação, foi de $10 \mathrm{kPa}$. Fabeiro et al. (2002), estudando o efeito do déficit hídrico em três fases da cultura do meloeiro (florescimento, pegamento de 
frutos e amadurecimento) verificaram que a produtividade e seus componentes (número de frutos por planta, peso e produção) foram significativamente influenciados pelo volume de água aplicado.

Apresenta-se, na Figura 3, a queda de rendimento em função do déficit hídrico aplicado durante a fase fenológica de pós-transplante/abertura da gema floral (experimento 1) e na fase fenológica de formação de frutos/colheita (experimento 2).

Uma equação de regressão linear foi ajustada passando pela origem. $\mathrm{O}$ coeficiente angular da equação, que representa o fator de resposta Ky, foi de 0,27 para a fase fenológica de póstransplante/abertura da gema floral e de 1,49 para a ase fenológica de formação dos frutos/colheita. De acordo com Doorenbos \& Kassan (1994), quando o déficit hídrico ocorre na fase inicial de desenvolvimento da cultura a queda do rendimento se torna proporcionalmente menor que o déficit hídrico aplicado $(\mathrm{ky}<1)$; já quando o déficit hídrico ocorre na fase produtiva, a queda relativa do rendimento é maior que a queda relativa da evapotranspiração, resultando em ky $>1$.

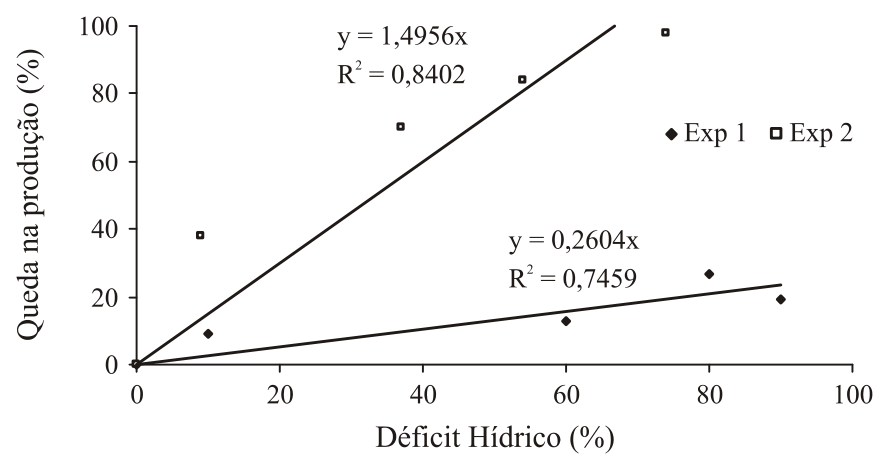

Figura 3. Q ueda de produção em função do déficit hídrico na fase pós-transplante/ abertura da gema floral (Exp 1) e na fase formação de frutos/colheita (Exp. 2) da cultura da berinjela

Verifica-se, portanto, que o fator de resposta de produção (Ky), foi maior no experimento 2, demonstrando maior sensibilidade da berinjela ao déficit hídrico durante a fase de formação de frutos/colheita. Valor semelhante foi obtido por Lovelli et al. (2007) que, trabalhando com quatro lâminas de irrigação na cultura de berinjela, encontraram valor para o fator de resposta de produção de 1,37 e com redução significativa da produtividade comercial, demonstrando a sensibilidade da cultura ao déficit hídrico. Arruda \& Grande (2003) estudaram o fator de resposta do café irrigado e não irrigado de um experimento conduzido durante 16 anos em Campinas, SP, e verificaram que o fator de resposta de produção $(\mathrm{Ky})$ anual mostrou-se linearmente crescente com a idade da planta, indicando aumento quanto à sensibilidade da cultura ao déficit hídrico, ao longo dos anos.

\section{CONCLUSÕES}

1. A berinjela foi mais sensível ao déficit hídrico na fase de formação dos frutos/colheita, na qual a produção, diâmetro do caule e altura da planta, apresentaram crescimento inversamente proporcional à tensão de água no solo.

2. A maior produtividade e crescimento de planta foram observados nos tratamentos irrigados com a tensão de $15 \mathrm{kPa}$.

\section{AGRADECIMENTOS}

À Coordenação de Aperfeiçoamento de Pessoal de Nível Superior - CAPES; à Fundação de Amparo à Pesquisa do Estado de Minas Gerais - FAPEMIG, e ao Departamento de Engenharia da Universidade Federal de Lavras.

\section{LITERATURA CITADA}

Antonini, A. C. C.; Robles, W. G. R.; Tessarioli Neto, J.; Kluge, R. A. Capacidade produtiva de cultivares de berinjela. Horticultura Brasileira, v.20, n.4, p.646-648, 2002.

Arruda, F. B.; Grande, M. A. Fator de resposta da produção do cafeeiro ao déficit hídrico em Campinas. Bragantia, v.62, n.1, p.139-145, 2003.

Aujla, M. S.; Thind, H. S.; Buttar, G. S. Fruit Yield and water use efficiency of eggplant (Solanum melongena L.) as influenced by different quantities of nitrogen and water applied through drip and furrow irrigation. Scientia Horticulturae, v.112, n.2, p.142-148, 2007.

Cardoso, M. O.; Pereira,W. E.; Oliveira, A. P. de; Souza, A. P. de. Eggplant growth as affected by bovine manure and magnesium thermophosphate rates. Scientia Agricola, v.65, n.1, p.77-86, 2008

Carvalho, J. A; Santana, M.; Pereira, G. M. Pereira, J. R. D.; Queiroz, T. M. Níveis de déficit hídrico em diferentes estádios fenológicos da cultura da berinjela (Solanum melongena L.). Engenharia Agrícola, v.24, n.2, p.320-327, 2004.

CFSEMG - Comissão de Fertilidade do Solo do Estado de Minas Gerais. Recomendações para o uso de corretivos e fertilizantes em Minas Gerais. In: Ribeiro, A. C.; Guimarães, P. T. G.; Alvarez V., V. H. (ed.), 5.ed. Lavras: CFSEMG, 1999. 359p.

Dantas, A. A. A.; Carvalho, L. G.; Ferreira, E. Classificação e tendências climáticas em Lavras, MG. Ciência e Agrotecnologia, v.31, n.6, p.1862-1866, 2007.

Doorenbos, J.; Kassam, A. H. Efeito da água no rendimento das culturas. Campina Grande: UFPB, 1994. 306p.

Dourado Neto, D.; Nielsen, D. R.; Hopmans, J. W.; Reichardt, K.; Bacchi, O. O. S. Software to model soil water retention curves (SWRC, version 3.00). Scientia Agricola, v.57, n.1, p.191-192, 2000.

EMBRAPA - Empresa Brasileira de Pesquisa Agropecuária. Centro Nacional de Pesquisa de Solos. Sistema brasileiro de classificação de solos. Brasília: Embrapa Produção de Informação; Rio de Janeiro: Embrapa Solos, 1999. 412p.

Fabeiro, C.; Santa Olalla, F. M. de; Juan, J. A. de. Production of muskmelon (Cucumis melo L.) under controlled deficit irrigation in a semi-arid climate. Agricultural Water Management, v.54, n.2, p.93-105, 2002.

Filgueira, F. A. R. Novo manual de olericultura: Agrotecnologia moderna na produção e comercialização de hortaliças. Viçosa: UFV, 2000. 402p. 
Gonçalves, M. da C. R.; Diniz, M. F. F. M.; Dantas, A. H. G.; Borba, J. R. C. Modesto efeito hipolipemiante do extrato seco de berinjela (Solanum melongena L.) em mulheres dislepidemias, sob controle nutricional. Revista Brasileira de Farmacognosia, v.16, suplemento, p.656-663, 2006.

Grangeiro, L. C.; Cecilio Filho, A. B. Exportação de nutrientes pelos frutos de melancia em função de épocas de cultivo, fontes e doses de potássio. Horticultura Brasileira, v.22, n.4, p.740-743, 2004.

Lovelli, S.; Perniolla, M.; Ferrara, A.; Tommaso, T. Di. Yield response factor to water (ky) and water use efficiency for Carthamus tinctorius L. and Solanum melongena L. Agricultural Water Management, v.92, n.1/2, p.73-80, 2007.

Marouelli, W. A.; Silva, W. L. C. Irrigação por gotejamento do tomateiro industrial durante o estádio de frutificação, na região de Cerrado. Horticultura Brasileira, v.24, n.3, p.342-346, 2006.

Marouelli, W. A.; SIlva, W. L. C.; Carrijo, O. A.; Silva, H. R. Produção e qualidade de alho sob regimes de água no solo e doses de nitrogênio. Horticultura Brasileira, v.20, n.2, p.191-194, 2002.

Marouelli, W. A.; Silva, W. L. C.; Silva, H. R. Manejo da irrigação em hortaliças. Brasília: Embrapa-SPI/Embrapa-CNPH, 1996. 72p.

Marques, D. C. Produção da berinjela (Solanum melongena L.) irrigada com diferentes lâminas e concentrações de sais na água., Lavras: UFLA, 2003. 55p. Dissertação Mestrado
Moura, D. C. M.; Carvalho, J. A.; Gomes, L. A. A. Evapotranspiração da cultura da berinjela irrigada com diferentes concentrações de sais na água. Engenharia Agrícola, v.15, p.1-6, 2004.

Posse, R. P.; Bernardo, S.; Sousa, E. F. de; Messias, G. P.; Monerat, P. H.; Gottardo, R. D. Relação entre a produtividade do mamoeiro e o déficit hídrico (ky) na região Norte Fluminense. Revista Brasileira de Engenharia Agrícola e Ambiental, v.13, n.2, p.158-164, 2009.

R Development Core Team. R: A language and environment for statistical computing: reference index version 2.8.0. Vienna Foundation for Statistical Computing, 2008. <http://www.Rproject.org.> 11 Jan.2008.

Ribeiro, C. S. C. Berinjela (Solanum melongena L.). Embrapa Hortaliças, Sistemas de Produção,3, VersãoEletrônica Nov/ 2007 <http://sistemasdeproducao.cnptia.embrapa.br/ FontesHTML/Beringela/Beringela_Solanum_melongena_L/ index.html > 1 Dez. 2008.

Sá, N. S. A. de; Pereira, G. M.; Alvarenga, M. A. R.; Mattioli, W.; Carvalho, J. e A. Comportamento da cultura do tomateiro sob diferentes tensões de água no solo em ambiente protegido. Revista Brasileira de Engenharia Agrícola e Ambiental, v.9, n.3, p.341-347, 2005.

Vilela, N. J.; Henz, G. P. Situação atual da participação das hortaliças no agronegócio brasileiro e perspectivas futuras. Cadernos de Ciência \& Tecnologia, v.17, n.1, p.71-89, 2000. 